\title{
American White Pelicans and Recreational Boaters on Lakes of the North American Great Plains: Habitat Use Overlap
}

\author{
Carolyn A. Gaudet and Christopher M. Somers*
}

Department of Biology, University of Regina, Regina, Saskatchewan, S4S 0A2, Canada

\begin{abstract}
Shoreline development and boating on lakes of the northern Great Plains of North America have increased due to recent economic prosperity. Few studies have examined the general characteristics of habitats used by foraging waterbirds and boats to determine levels of overlap. To address this issue, we conducted point count surveys of American White Pelicans (Pelecanus erythrorhynchos) and boats on two important recreational lakes in southern Saskatchewan, Canada. The majority of pelicans and boats detected used near-shore areas of the lakes, identifying the importance of shallow water habitats and providing evidence of significant overlap. The location of pelicans relative to the shore did not change in the presence of boats, and there was no significant relationship between boat numbers and pelican numbers. These analyses suggest that pelicans did not make major changes to their habitat use on the lakes as a result of boating activity. When pelicans and boats were present simultaneously at point count locations, pelicans appeared to avoid boats on one lake, but showed no detectable avoidance behavior on the other lake. The importance of interactions between recreational boating and foraging pelicans is currently unclear. Set-back distances to protect foraging pelicans from boating activity do not appear necessary based on our analyses.
\end{abstract}

Keywords: Habitat use, lake use, Pelecanus erythrorhynchos, recreational boating disturbance.

\section{INTRODUCTION}

Human population growth and economic prosperity is causing increased recreational use of lakes on the Canadian Great Plains. Waterbirds in this region are therefore potentially exposed to increased levels of human disturbance, including boating, shoreline development, and ecotourism. Recreational uses can have negative effects on birds that share aquatic habitats with humans; for example, recreational boat presence and movement can cause disturbance whereby birds flush, leading to use of sub-optimal habitats, lost food resources, or increased nest failure and chick predation in breeding birds [1-3]. Currently, little is known about interactions between waterbirds and recreational boaters on lakes of the North American Great Plains.

The American White Pelican (Pelecanus erythrorhynchos; hereafter, pelican) is the largest colonial waterbird species in North America. Pelicans nest in many locations on lakes and wetlands throughout the Great Plains, including south-central Canada [4]. During the history of human settlement of the Great Plains, pelicans have been considered both a nuisance species because of their piscivorous diet [5], and also a species of conservation concern due to widespread declines caused by human persecution ([4]; listed as 'Threatened' by the Committee on the Status of Endangered Wildlife in Canada until 1987). The colonial nature of pelicans, their limited distribution, low productivity, and the small number of colonies North America-wide make them vulnerable to disturbance at breeding colonies. However, since

\footnotetext{
*Address correspondence to this author at the Department of Biology, University of Regina, Regina, Saskatchewan, S4S 0A2, Canada; Tel: (306)585-4850; E-mail: chris.somers@uregina.ca
}

pelicans were removed from the Species at Risk list in Canada in 1987, numbers have grown on the northern Great Plains and other portions of their range, and they are now more numerous than they have been for many years [6]. Thus, pelicans and humans are more abundant on the Great Plains, especially in Canada, than at any previous time in recorded history. Fish-bearing lakes suitable for both piscivorous birds and human recreation are relatively rare on the Great Plains, so habitat use overlap between pelicans and humans is a distinct possibility. However, habitat use by pelicans and humans on the same lakes has not been previously investigated.

Previous research on waterbird disturbance has often focused on the behavioural responses shown by individuals, such as flush distance $[7,8]$, the time required for birds to return to foraging or incubating/brooding, and the foraging time lost due to different disturbances, such as large boats versus personal water crafts [3]. The different responses documented likely depend on the level of stress the individuals are experiencing [9]. Pelicans have been documented to flush in response to boats at greater distances than other waterbirds, which is likely a function of the increased time it takes them to lift off of the water compared to smaller species [3]. However, measuring these behaviours does not permit us to evaluate whether disturbance changes the distribution and habitat use of birds due to habitat overlap.

The potential for habitat overlap and disturbance effects involving pelicans and humans on lakes in the southern portion of the Canadian province of Saskatchewan is high. Few large lakes exist in this region and all have relatively intense recreational use. Recent demand for recreational properties and boating opportunities on these lakes is much greater than 
in previous decades, and the pelican population in Saskatchewan has concurrently increased from a low of $\sim 4,500$ breeding pairs in the mid-1970's [10], to over 30,000 pairs in the province as of 2006 [11]. Consequently, it is important to understand habitat use overlap by pelicans and humans in southern Saskatchewan, and the potential for human disturbance effects. Accordingly, our study objectives were to: (1) identify some basic features of aquatic habitats used by pelicans and boats on two recreationally important lakes in southern Saskatchewan, and (2) examine potential effects of boats on the distribution of foraging pelicans on these lakes.

\section{Study Area}

Our study was conducted on Last Mountain (LML) and Buffalo Pound (BPL) Lakes in southern Saskatchewan (Fig. 1). Both lakes are part of the Qu'Appelle River watershed, the largest in a low-precipitation area, and are used extensively for recreation, including development of the shoreline for cottages, and boating for water sports and angling [12]. Lakes in the Qu'Appelle River system support 20-25 fish species, and are important breeding and staging area for shorebirds, waterfowl, and avian piscivores. LML is a long, narrow (maximum width $4.5 \mathrm{~km}$ ), prairie lake, located at $51^{\circ} 20^{\prime} \mathrm{N}, 105^{\circ} 14^{\prime} \mathrm{W}$. It is eutrophic with an average depth of $7.6 \mathrm{~m}$, a maximum depth of $30 \mathrm{~m}$, and a surface area of $233 \mathrm{~km}^{2}$. LML has diverse aquatic habitats, such as shallow wetlands, islands, emergent shoals, and depth heterogeneity along its length. Buffalo Pound Lake is a small, narrow (maximum width $1.25 \mathrm{~km}$ ) reservoir located at $50^{\circ} 40^{\prime} \mathrm{N}, 105^{\circ} 30^{\prime} \mathrm{W}$. It is eutrophic with a mean depth of 3.0 $\mathrm{m}$, a maximum depth of $5.6 \mathrm{~m}$, and a surface area of 29.5 $\mathrm{km}^{2}$. BPL varies little in depth along its length and has relatively little aquatic habitat heterogeneity. Both lakes have important foraging areas for aquatic birds and are used regularly by pelicans and other piscivorous waterbirds. In addition, both lakes are sufficiently narrow that pelicans and boats can be clearly observed on the water with binoculars and spotting scopes from points along the shoreline. LML has an active pelican breeding colony with an estimated 1,600 nesting pairs in 2007 when this study was conducted. BPL does not have a breeding colony but foraging pelicans are present on this lake throughout the spring and summer.

\section{METHODS}

\section{Pelican and Boat Counts}

We conducted systematic point counts of pelicans and boats at 20 fixed locations on the east shore of LML and 18 locations on the south shore of BPL (Figs. 2 and 3). The points were selected to cover the complete lengths of both lakes with approximately equal distance between them $(\sim 4$ $\mathrm{km}$ on LML and $\sim 2 \mathrm{~km}$ on BPL). The size of the field of view at each point was different, but combined the areas from all points covered $\sim 100 \mathrm{~km}^{2}(43 \%)$ of the surface area of LML and $25 \mathrm{~km}^{2}$ (84\%) of the surface area of BPL. At each point we counted all pelicans and boats within the field of view and marked their estimated locations on a bathymetric map of the lake. For this study we only included birds observed on the water in our analyses; birds loafing on land were excluded. All types of watercraft, ranging from highpowered motorboats to canoes, were recorded; we did not consider boat type in our analyses. Lake-wide point counts were conducted approximately twice per week, once on a weekday and once on the weekend, on 22 days between 16May and 7-August 2007 on LML and 18-May and 8-August 2007 on BPL. To conduct counts, 2 observers panned the complete field of view at each point count location using 10 x 50 binoculars (Bushnell perma-focus) and independently counted all birds and boats visible. We accepted counts when the two observers reported values that were within $10 \%$ of each other; otherwise counts were repeated (after a short delay) until values were within the $10 \%$ margin. We recorded and used the higher of the two count values in all cases. Observers discussed and agreed upon the location of birds and boats using shoreline landmarks as reference points, and marked all observations on a detailed contour map of the lake. Distance values were then calculated later from the maps.

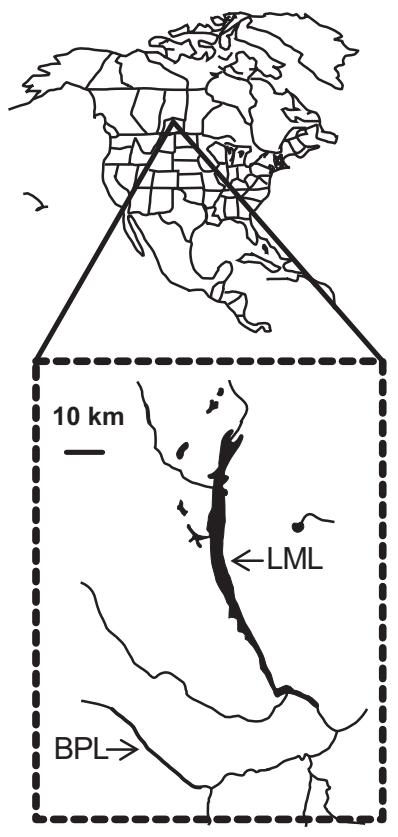

Fig. (1). The locations of Last Mountain (LML) and Buffalo Pound (BPL) Lakes in southern Saskatchewan, Canada (top = map of North America).

\section{Data Analysis}

Habitat characteristics. - For both lakes we attempted to estimate the distance from shore to all pelicans and boats observed. We chose this metric as a proxy for water depth based on bathymetric maps. We also estimated water depth used by pelicans and boats based on their estimated locations on bathymetric maps. On LML, we used the location of pelicans and boats marked on detailed lake maps to directly estimate their distance from shore when they were within 500 $\mathrm{m}$ of either shoreline, or in areas of the lake $<1 \mathrm{~km}$ across. Pelicans and boats further than $500 \mathrm{~m}$ from shore in areas of the lake $>1 \mathrm{~km}$ wide were assigned to a $500 \mathrm{~m} \times 500 \mathrm{~m}$ square, and the distance from shore was measured to the center of the square. This system was adopted to reflect the uncertainty of estimating the location of distant objects on the water surface. We categorized observations as belonging 


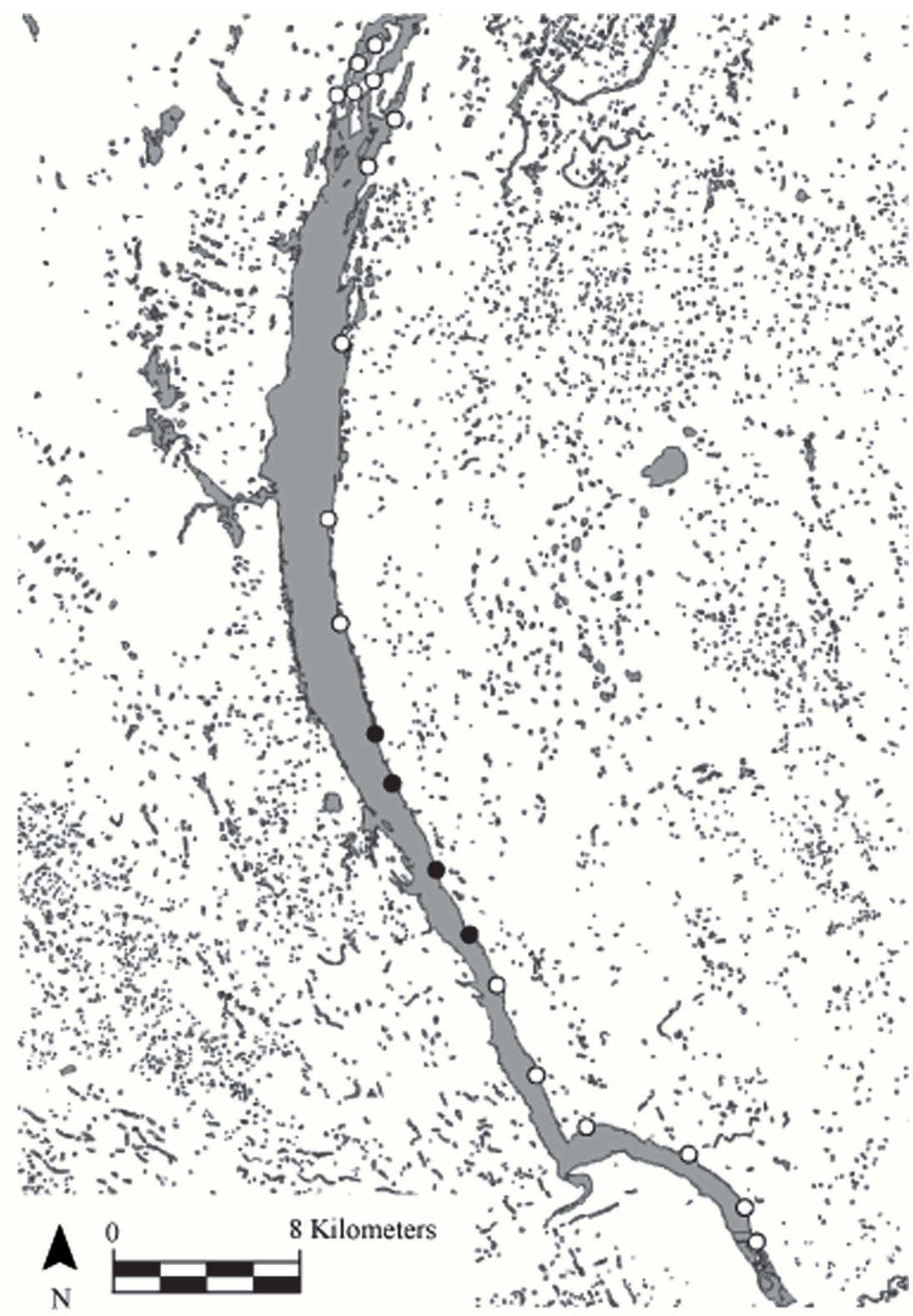

Fig. (2). The location of point count stations on the east shore of Last Mountain Lake. These points were visited on 22 days from mid-May to mid-August 2007 to conduct lake-wide counts of pelicans and boats. All stations, indicated by a circle (O), are included in the whole lake analyses. Black circles $(\bullet)$ indicate the stations designated for the high-use section analyses.

to one of three distance from shore categories: 1) $0-0.5 \mathrm{~km}$, 2) $0.5-1.0 \mathrm{~km}$ and 3$)>1.0 \mathrm{~km}$. The area of each distance from shore category represented within the field of view varied by point count location according to the width of the lake (Fig. 2). The furthest distance category $(>1.0 \mathrm{~km})$ was present only in the middle of LML, and some locations at the north end contained only the $0-0.5 \mathrm{~km}$ category. To characterize general patterns over the whole lake, we pooled count data from all point count locations. Approximately $50 \%$ of the surveyed area was $0-0.5 \mathrm{~km}, 27 \%$ was $0.5-1.0 \mathrm{~km}$, and $23 \%$ was $>1.0 \mathrm{~km}$ from shore. We collected similar data for BPL, but because it is much narrower than LML the location of pelicans and boats was estimated directly from the marked location on maps for all observations. The distance from shore categories for BPL were: 1) 0-0.125 km, 2) 0.125-0.25 $\mathrm{km}, 3) 0.25-0.375 \mathrm{~km}$ and 4) $>0.375 \mathrm{~km}$. BPL is relatively uniform in width (Fig. 3), so each distance from category composed approximately $25 \%$ of the total area surveyed.

We calculated the daily total proportions of pelicans and boats in each of the distance from shore categories at all points combined, and then the mean proportion of each across the 22 lake-wide point counts conducted. The proportion of pelicans and boats in each category on LML and BPL was then compared using a two-way analyses of variance (ANOVA), with study subject (pelican or boat), and distance category as the independent variables. We chose to work with proportions because pelican numbers on the lakes were considerably larger than boat numbers, so using the observed 


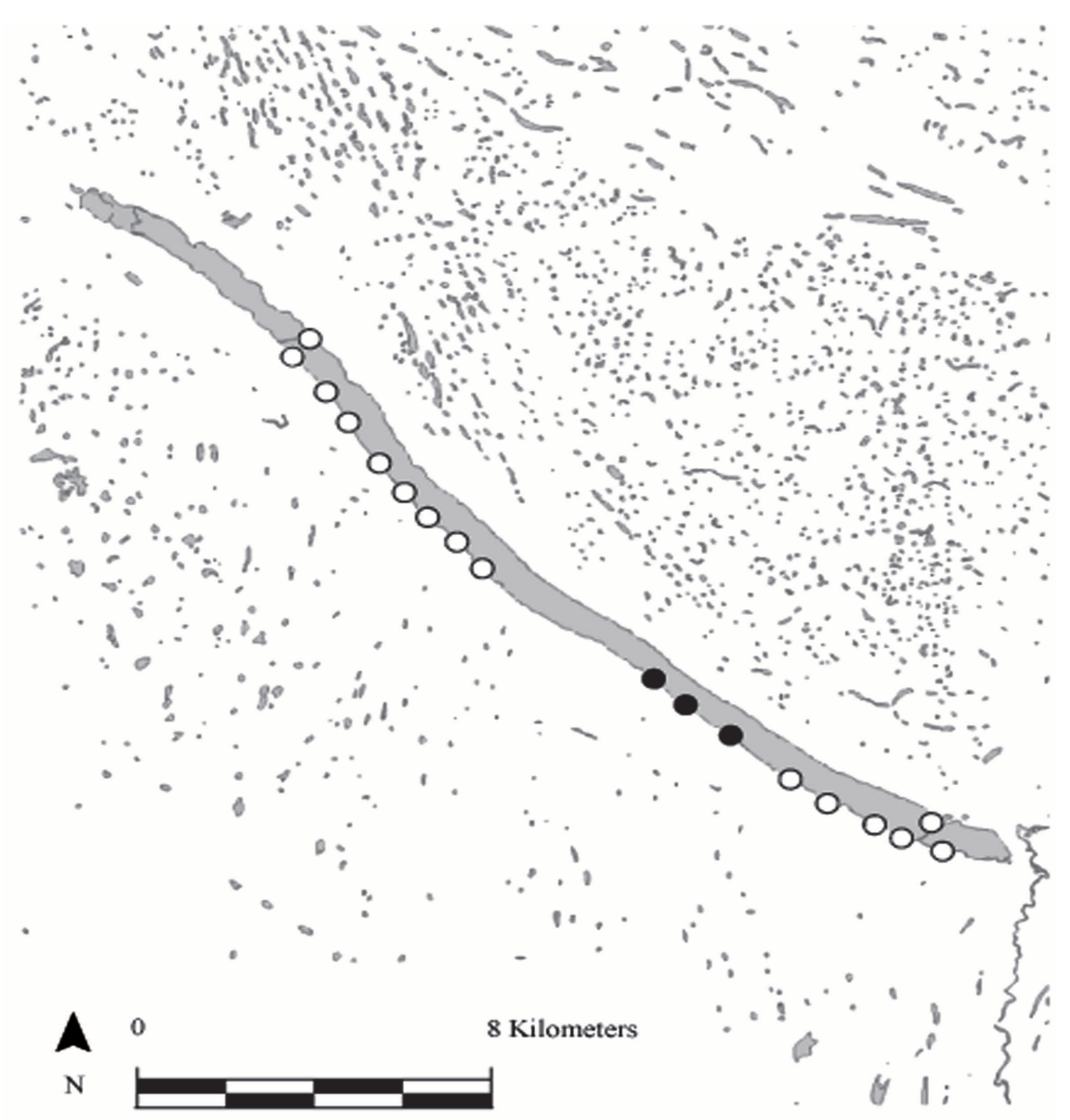

Fig. (3). The locations of the point count stations on the south shore of Buffalo Pound Lake. These points were visited on 22 days from midMay to mid-August 2007 to conduct lake-wide counts of pelicans and boats. All stations, indicated by a circle (O), are included in the whole lake analyses. Black circles $(\mathbf{)})$ indicate the stations used in the high-use section analyses.

numbers of each or density did not allow a meaningful comparison between them. All proportions were arcsine transformed to meet the assumptions of normality and homoscedasticity; figures based on proportion data display backtransformed means and 95\% confidence intervals. Tukey's test was used for post-hoc comparisons following a significant $(\mathrm{P}<0.05)$ outcome of ANOVA. We performed additional analyses (ANOVA) of pelican and boat numbers in a smaller sub-section of each lake that had high levels of human use and large numbers of pelicans. We conducted this analysis to ensure that lake-wide patterns were representative of locations with maximal human-pelican interaction. For LML we analyzed pooled data from 4 point count locations in a middle section of the lake that had substantial shoreline development and all distance to shore categories. We chose a similar section with 3 point count locations in the middle of BPL (Figs. 2 and 3).

The distribution of pelicans. - Using two-way ANOVA we analyzed the distance from shore categories occupied by pelicans separately based on whether or not boats were present at each point count location. Daily pelican count data from each point count station were log-transformed to meet the assumptions of normality and homoscedasticity; we only used count data when pelicans were present, negating the need to adjust for zero values in the log-transformation. Figures comparing count data in the presence and absence of boats display back-transformed means and $95 \%$ confidence intervals. Tukey's test was used for post-hoc comparisons following a significant outcome of ANOVA. We then used Spearman rank correlation tests to examine the relationship between the total number of boats and pelicans observed in each distance from shore category on each day in the same high-use sections of LML and BPL described above. For BPL, the last two distance from shore categories, 0.25-0.375 $\mathrm{km}$ and $>0.375 \mathrm{~km}$, were grouped as $>0.25 \mathrm{~km}$ as there was not enough data in the $>0.375 \mathrm{~km}$ category to test for a relationship.

Distance from boats. - The potential for pelicans to avoid boats was examined by estimating the distance of birds from boats based on their marked location on maps when both were present at the same points on lakes. On LML pelicans were assigned to one of 4 distance categories from boats: 1) $<500 \mathrm{~m}$, 2) 500-1000 m, 3) 1000-1500 m, and 4) > $1500 \mathrm{~m}$. When groups of boats, defined as two or more boats within $500 \mathrm{~m}$ of each other, were in the same field of view as pelicans, the boat closest to the pelicans was used to estimate the distance category. We totalled the number of pelicans assigned to each distance category on each day, and calculated 
the mean over the 22 days of data collection at all point count locations. On BPL we performed similar data collection, but we assigned pelicans to one of 3 distance categories: 1) $<500 \mathrm{~m}$, 2) 500-1000 $\mathrm{m}$, and 3) $>1000 \mathrm{~m}$ in accordance with the smaller width of the lake. All pelican count data were log-transformed and compared among distance categories using one-way ANOVA; figures displaying the data show back-transformed means and 95\% confidence intervals.

\section{RESULTS}

\section{Habitat Characteristics}

Last Mountain Lake. - We recorded a range of 0 to 519 pelicans $($ median $=200)$ and 0 to 162 boats $($ median $=39)$ daily on LML. Pelicans and boats appeared to use similar water depths on average at each point count location on LML, and tended to use shallower water preferentially (Table 1). The proportion of pelicans and boats varied significantly among the three distance from shore categories on LML (Fig 4A, ANOVA, $F_{2,125}=56.35, \mathrm{P}<0.01$ ). On average the proportion of pelicans in the $0-0.5 \mathrm{~km}$ from shore category was 3 -fold higher than the next closest one, and for boats it was 6 -fold higher. This interaction between distance from shore categories and study subject was significant (Fig 4A, ANOVA, $\mathrm{F}_{2,125}=10.18, \mathrm{P}<0.01$ ). Pelicans and boats evidently differed somewhat in their use of aquatic habitats on the lake.
Four points in the middle section of LML were chosen for separate analysis to determine whether the results obtained at the whole lake level were similar to those in a section with high potential for habitat use overlap between pelicans and boats. We recorded a range of 0 to 209 pelicans $($ median $=37)$ and 0 to 25 boats $($ median $=9)$ in this section daily over the 22 lake-wide point counts. As in the wholelake analysis, the distributions of pelicans and boats over the distance categories differed significantly (Fig. 4B, ANOVA, $\left.\mathrm{F}_{2,125}=19.90, \mathrm{P}<0.01\right)$. Both pelicans and boats were more abundant near the shore, but this was especially true for boats as indicated by a significant interaction between distance categories and study subject (Fig. 4B, ANOVA, F 2,125 $=2.99, \mathrm{P}<0.05)$. On average a two-fold higher proportion of boats were found in the $0-0.5 \mathrm{~km}$ category than of pelicans.

Buffalo Pound Lake. - We recorded a range of 0 to 72 pelicans $($ median $=20)$ and 1 to 94 boats $($ median $=6)$ on BPL over the 22 lake-wide point counts. Pelicans and boats appeared to use similar water depths on average, both preferring shallower waters (Table 2). As at LML, the proportions of both pelicans and boats varied significantly among the distance from shore categories on BPL (Fig. 5A, ANOVA, $\left.\mathrm{F}_{3,171}=54.86, \mathrm{P}<0.01\right)$. This main effect was caused largely by the proportion of pelicans being more than 25 -fold higher on average in the $0-0.125 \mathrm{~km}$ category than the next closest one. In contrast, boats were more evenly spread among the different distance from shore categories. A significant inter-

Table 1. Average water depth $(\mathrm{m})$ used by pelicans and boats on Last Mountain Lake and the range of depths available at each point. The point count location numbers begin at the northern end of Last Mountain Lake and proceed south along the east shore in numerical order (see Fig. 2). The average depths used by pelicans and boats on point counts 1-4 were not recorded because no depths were identified on the bathymetric map (all depths less than $5 \mathrm{~m}$ ). Means represent all detections at each point over the 22 days in 2007.

\begin{tabular}{|c|c|c|c|}
\hline Point Count Location \# & $\begin{array}{c}\text { Pelicans } \\
(\text { mean depth } \pm \text { SD) }\end{array}$ & $\begin{array}{c}\text { Boats } \\
(\text { mean depth } \pm \text { SD) }\end{array}$ & Depth Range Available \\
\hline $1-4$ & not recorded & not recorded & $<5$ \\
\hline 5 & $3.6 \pm 3.2$ & $2.5 \pm 0.0$ & $0-5$ \\
\hline 6 & $4.9 \pm 3.0$ & $4.7 \pm 0.8$ & $0-10$ \\
\hline 8 & $7.0 \pm 4.6$ & $10.3 \pm 4.9$ & $0-15$ \\
\hline 9 & $9.8 \pm 7.0$ & $7.8 \pm 5.8$ & $0-25$ \\
\hline 10 & $12.3 \pm 7.6$ & $10.4 \pm 7.4$ & $0-30$ \\
\hline 11 & $14.0 \pm 6.5$ & $14.6 \pm 8.4$ & $0-25$ \\
\hline 14 & $5.3 \pm 3.1$ & $7.7 \pm 2.7$ & $0-10$ \\
\hline 15 & $4.0 \pm 1.4$ & $3.9 \pm 1.7$ & $0-10$ \\
\hline 16 & $2.7 \pm 0.7$ & $3.6 \pm 1.2$ & $0-5$ \\
\hline 17 & $2.5 \pm 0.0$ & $2.9 \pm 0.9$ & $<5$ \\
\hline 18 & $2.5 \pm 0.0$ & $2.5 \pm 0.0$ & $<5$ \\
\hline
\end{tabular}


action between distance to shore and study subject (Fig. 5A, ANOVA, $\left.\mathrm{F}_{3,171}=29.94, \mathrm{P}<0.01\right)$ reflected a nearly 8 -fold higher proportion of pelicans than of boats in the $0-0.125 \mathrm{~km}$ category.

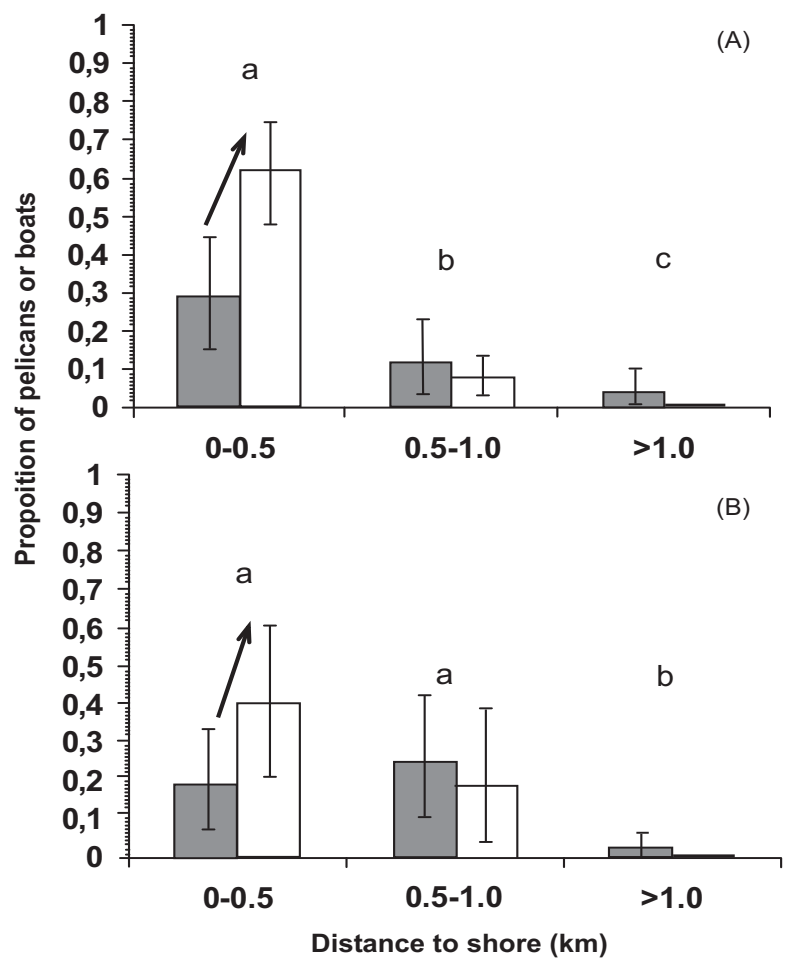

Fig. (4). The mean proportions $( \pm 95 \% \mathrm{CI})$ of pelicans $(\square)$ and boats $(\square)$ observed in different distance-to-shore categories on Last Mountain Lake at (A) all points, and (B) in the high-use section only, over 22 days in 2007. Different letters above bars indicate groups that are significantly different from one another in post-hoc tests following ANOVA; arrows indicate significant pair-wise interactions.

Three points in the middle section of BPL were chosen for separate analysis to determine whether the results obtained at the whole lake level were similar in a section with high potential for habitat use overlap between pelicans and boats. We recorded a range of 0 to 30 pelicans $($ median $=4$ ) and 0 to 40 boats (median $=1$ ) in this section daily over the 22 point counts. As in the whole lake analyses, neither pelicans or boats were distributed evenly among the distance from shore categories (Fig. 5B, ANOVA, $\mathrm{F}_{3,119}=38.12, \mathrm{P}<$ $0.01)$. The proportion of pelicans in the $0-0.125 \mathrm{~km}$ category was more than 25-fold higher than the proportion in the next closest category. In contrast, the proportion of boats in the 0 $0.125 \mathrm{~km}$ category was only $\sim 2$-fold higher than the next one, producing a significant interaction between distancefrom-shore and study subject in this lake section (Fig. 5B, ANOVA, $\left.\mathrm{F}_{3,119}=9.51, \mathrm{P}<0.01\right)$ that paralleled that for the whole lake.

\section{Distribution of Pelicans}

Effect of boats. - We analyzed the distance from shore data for pelicans separately based on the presence of boats at point count locations to determine whether the birds changed distribution in the presence of boats. On LML, the number of pelicans in each distance from shore category did not vary significantly in the presence or absence of boats (Fig. 6A, ANOVA, $\left.\mathrm{F}_{1,1357}=1.0, \mathrm{P}=0.97\right)$. There was also no significant interaction between distance from shore category and boat presence / absence (Fig. 6A, ANOVA, $\mathrm{F}_{2,1357}=0.84, \mathrm{P}$ $=0.43)$. On BPL, pelican counts in the different distancefrom-shore categories also did not vary significantly in the presence or absence of boats (Fig. 6B, ANOVA, $\mathrm{F}_{1,248}=$ $1.47, \mathrm{P}=0.22$ ), nor was there evidence of an interaction between the distance from shore category and boat presence / absence (Fig. 6B, ANOVA, F $3,248=0.87, \mathrm{P}=0.46$ ).

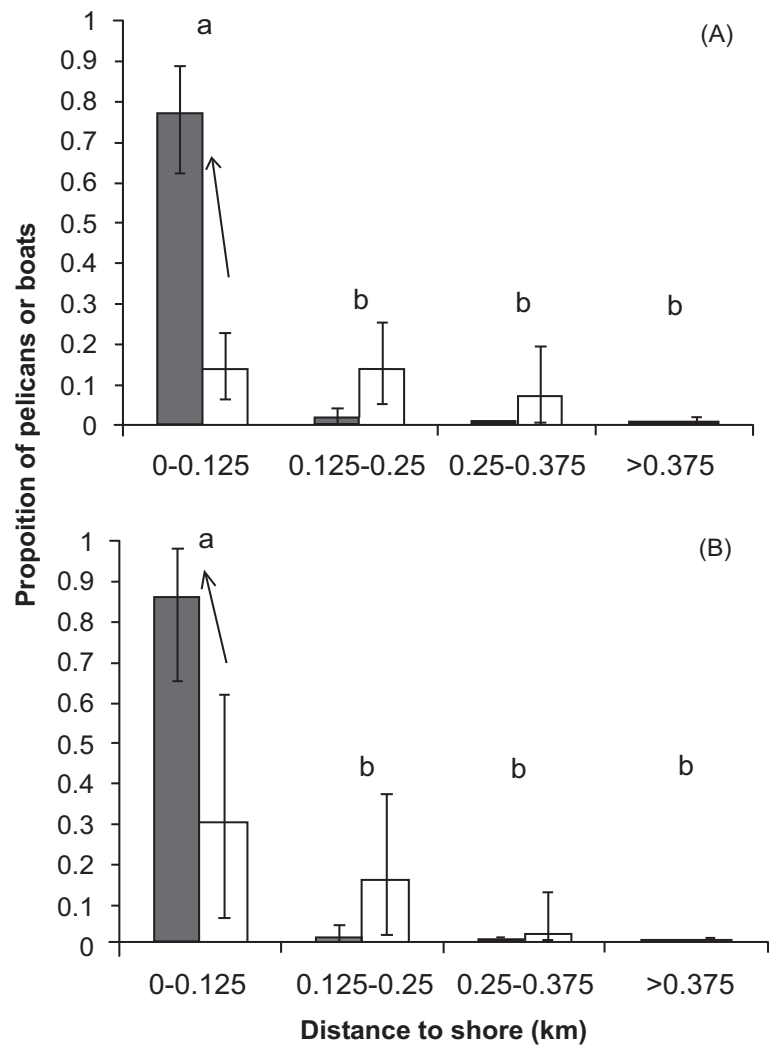

Fig. (5). The mean proportions $( \pm 95 \% \mathrm{CI})$ of pelicans $(\square)$ and boats $(\square$ ) observed in different distance-to-shore categories on Buffalo Pound Lake at (A) all points, and (B) in the high-use section only, over 22 days in 2007. Different letters above bars indicate groups that are significantly different from one another in post-hoc tests following ANOVA; arrows indicate significant pair-wise interactions.

The analysis of pelican habitat use in the presence vs. absence of boats above may lack sensitivity because it does not take into account boat number. Therefore, for each distance category, Spearman rank correlation coefficients $(\rho)$ for numbers of pelicans versus boats were calculated. No significant correlations were found $(0-0.5 \mathrm{~km}: \rho=0.33, \mathrm{P}=$ $0.13 ; 0.5-1.0 \mathrm{~km}: \rho=0.30, \mathrm{P}=0.17 ;>1.0 \mathrm{~km}: \rho=0.21, \mathrm{P}=$ $0.34)$. On BPL there was also no correlation between the numbers of pelicans and boats in any of the distance from shore categories in the high use area of the lake $(0-0.125 \mathrm{~km}$ : $\rho=-0.12, \mathrm{P}=0.60 ; 0.125-0.25 \mathrm{~km}: \rho=-0.036, \mathrm{P}=0.88 ;>$ $0.25 \mathrm{~km}: \rho=-0.11, \mathrm{P}=0.65)$. 
Table 2. Average water depth $(\mathrm{m})$ used by pelicans and boats on Buffalo Pound Lake and the depth range available at each point. The point count location numbers begin at the eastern end of Buffalo Pound Lake and proceed in numerical order along the south shore of the lake (see Fig. 3). Means represent all detections at each point over the 22 days in 2007.

\begin{tabular}{|c|c|c|c|}
\hline Point count location \# & $\begin{array}{c}\text { Pelicans } \\
(\text { mean depth } \pm \text { SD) }\end{array}$ & $\begin{array}{c}\text { Boats } \\
(\text { mean depth } \pm \text { SD) }\end{array}$ & Depth range available \\
\hline 1 & $1 \pm 0.0$ & $0.0 \pm 0.0$ & $0-1$ \\
\hline 2.1 & $1.1 \pm 0.3$ & $0.0 \pm 0.0$ & $0-1.5$ \\
\hline 3 & $2.6 \pm 0.7$ & $2.4 \pm 0.6$ & $0-3.5$ \\
\hline 5 & $3.5 \pm 1.3$ & $4.2 \pm 0.5$ & $0-4.5$ \\
\hline 6 & $3.6 \pm 0.5$ & $3.7 \pm 1.1$ & $0-4.8$ \\
\hline 7 & $3.7 \pm 1.0$ & $3.8 \pm 0.8$ & $0-5.1$ \\
\hline 8 & $3.3 \pm 1.0$ & $3.1 \pm 1.1$ & $0-5.1$ \\
\hline 12 & $3.0 \pm 0.4$ & $3.5 \pm 1.0$ & $0-4.9$ \\
\hline 13 & $3.2 \pm 1.4$ & $3.4 \pm 1.2$ & $0-4.9$ \\
\hline 14 & $3.8 \pm 0.6$ & $3.7 \pm 0.8$ & $0-4.6$ \\
\hline 15 & $2.7 \pm 1.4$ & $3.6 \pm 0.8$ & $0-4.3$ \\
\hline 16 & $3.4 \pm 0.6$ & $3.2 \pm 0.7$ & $0-3.9$ \\
\hline 17 & $2.8 \pm 0.7$ & $3.1 \pm 0.5$ & $0-3.6$ \\
\hline 18 & $2.1 \pm 0.5$ & $2.4 \pm 0.6$ & $0-3.5$ \\
\hline
\end{tabular}

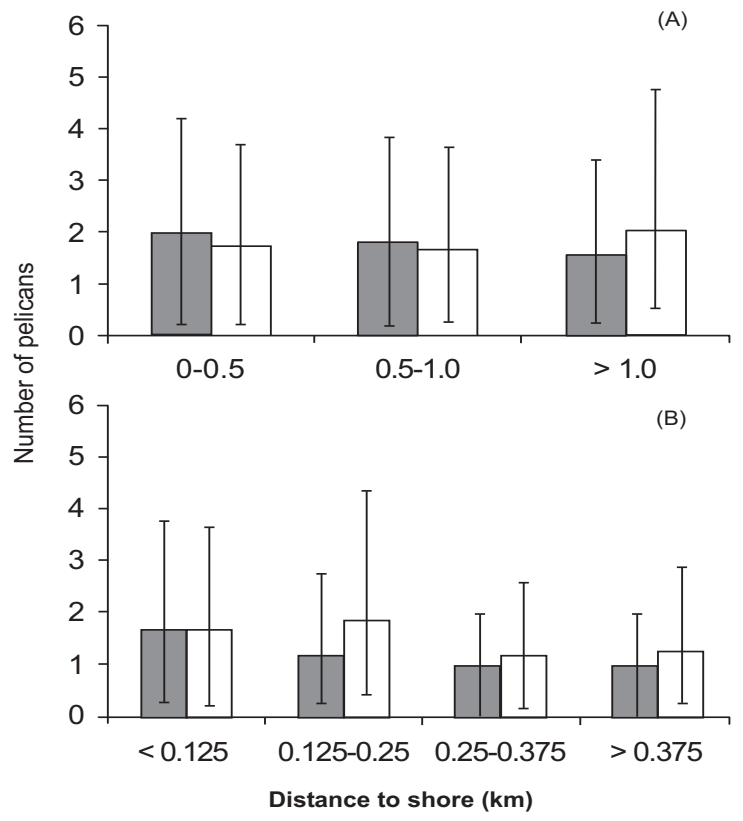

Fig. (6). The geometric mean number of pelicans observed $( \pm 95 \%$ CI) in the presence $(\square)$ or absence $(\square)$ of boats in different distance from shore categories on (A) Last Mountain Lake, and (B) Buffalo Pound Lake, over 22 days. The total area surveyed in each distance category varied as described in the methods. There were no significant main effects or interactions detected.
Distance from Boats. - Distance from the nearest boat(s) explained a significant proportion of the variance in pelican counts on LML (Fig. 7; ANOVA, $\mathrm{F}_{3,285}=11.87, \mathrm{P}<0.01$ ). More than twice as many pelicans were found in the $>1500$ $\mathrm{m}$ distance category as in the others. This finding is consistent with the prediction that disturbance causes pelicans to move away from, or avoid boats. However, the data should be interpreted with caution because the $>1500 \mathrm{~m}$ distance category was spatially much larger than the others, and may therefore have had more pelicans in it simply as an area effect. In contrast to findings on LML, distance from the nearest boat only marginally affected pelican counts on BPL (Fig. 8; ANOVA, F 2,60 $=3.03, \mathrm{P}=0.06$ ).

\section{DISCUSSION}

\section{Habitat Characteristics}

Distance from shore influenced the location of pelicans and boats on both of our study lakes. On both LML and BPL, there was extensive habitat use overlap by pelicans and boats based on their locations relative to the shore. Depths used by pelicans and boats were similar at most point count locations, with both preferring shallower waters. The proportions of pelicans and boats in each distance from shore category differed somewhat. On average $50 \%$ of pelicans and close to $80 \%$ of boats counted on LML were $<500 \mathrm{~m}$ from shore, and on BPL over $90 \%$ of pelicans and $70 \%$ of boats counted were $<250 \mathrm{~m}$ from shore. An almost identical pat- 
tern was identified in high-use areas of both lakes, indicating that lake-wide data were not confounded by observations in areas with many pelicans and no boats, or vice versa. In sum, our data show potentially important overlap between pelicans and humans in shallow water habitats.

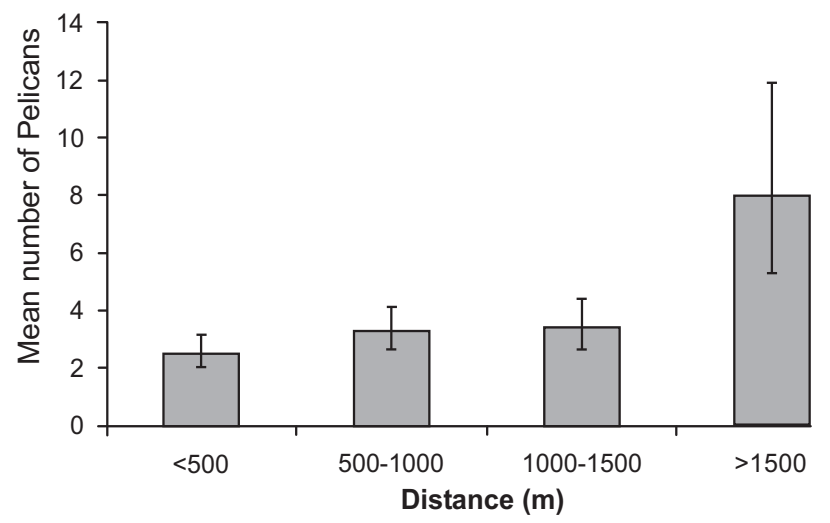

Fig. (7). The geometric mean $( \pm 95 \% \mathrm{CI})$ number of pelicans in four distance categories from boats when they were both observed simultaneously at the same point count locations on Last Mountain Lake. Different letters = groups that are significantly different from one another based on post hoc testing following ANOVA.

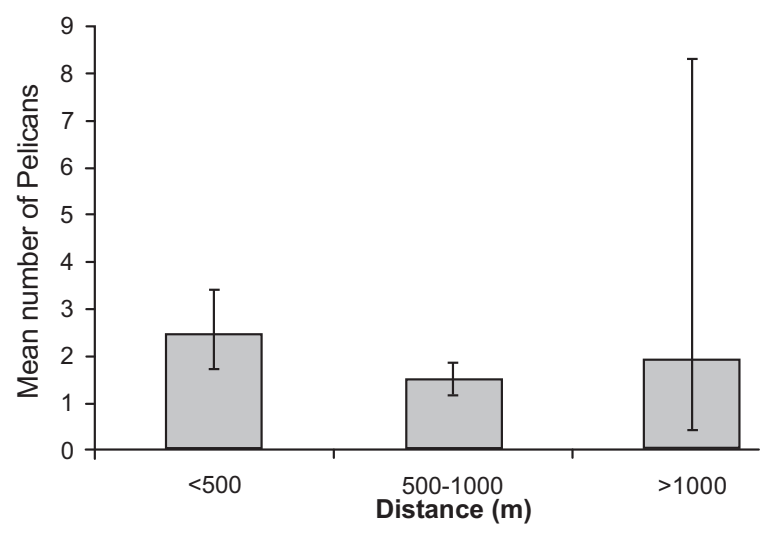

Fig. (8). The geometric mean $( \pm 95 \% \mathrm{CI})$ number of pelicans in three distance categories from boats when they were both observed simultaneously at the same point count locations on Buffalo Pound Lake. Means were not significantly different from one another.

Prey availability (sensu [13]) and foraging strategy likely explain the distribution of pelicans on both of our study lakes. Pelicans observed swimming are likely foraging [14], so we expected to observe swimming pelicans most often in the shallowest water near shore where they would be able to reach prey from the surface to the bottom of the water column using their surface-dipping approach $[6,15]$. As predicted, we did find most pelicans in near shore areas, emphasizing the importance of shallow water habitats for these birds. However, we also found a substantial number of pelicans in off shore pelagic areas, particularly in large foraging flocks ( $>100$ birds). Previous studies $[13,16]$ have identified littoral zones and shallow bays as critical foraging habitats for pelicans, although deeper water sites were also used, as observed in our study. Pelicans have also been observed co-foraging in deeper water with Double Crested Cormorants (Phalacrocorax auritus), and it has been proposed that they might benefit from cormorants flushing prey towards the surface, allowing pelicans to sometimes forage successfully in pelagic zones [17]. Based on behavioural analyses (e.g., [14]) we assume that the pelicans we observed in offshore pelagic areas were foraging; however, it is possible that they were simply resting on the water surface. Nevertheless, the potential for conflict between pelicans and boaters is highest in shallow, near-shore areas on our study lakes.

Our counts included every boat type from small, quiet crafts (canoes, sail boats and kayaks) to high-powered motorboats, with nearly half of boats on both lakes being motorized fishing boats. The distribution of boats containing anglers is likely influenced by the location of aquatic habitats frequented by their target fish species. Different species of fish use habitat with specific characteristics; for example, the popular angling species yellow perch and northern pike primarily use littoral habitats $[18,19]$, whereas walleye prefer open water zones [20]. Thus, anglers targeting perch and pike in near shore areas are likely using prime pelican foraging habitats in shallow water, whereas those pursuing walleye are more likely in more pelagic zones that are less important for birds, other than the larger flocks observed periodically in open water. Boats engaging in water sports other than angling may prefer near-shore areas to minimize exposure to wave action and the distance to travel to shore in the event of inclement weather. Regardless of motivation, it is clear that recreational boats and pelicans often overlapped in near-shore habitat use, an observation that has also been made for boats and piscivorous birds in other systems [21].

\section{Distribution of Pelicans}

Pelicans and recreational boaters used similar aquatic habitats on LML and BPL, but pelicans did not appear to respond numerically or spatially to this overlap. Boat presence did not affect pelican distribution among the different distance from shore categories; i.e., pelicans did not distribute themselves differently when boats were present vs. when they were absent (although their numbers tended to be somewhat lower when boats were present). Lack of significant correlation between the number of boats and the number of pelicans on high use sections of LML or BPL suggested that the birds did not respond to boating activity by leaving the habitat, at least in terms of the distance from shore categories. In previous studies pelicans and other pelecaniforms became attentive but did not flush or move away unless directly approached by humans [22]. It is therefore possible that the spatial and numerical responses we attempted to examine here were too large in scale to detect pelican responses to boats. For example, if pelicans simply moved a few hundred meters away from boats, but remained in the same distance from shore category, we would not have detected any change in habitat use. Thus, future studies of this kind must employ higher precision in documenting pelican behavior in response to boats. In addition, habituation to boat presence may be occurring on LML and BPL, which would make pelicans widespread regardless of the level of development or activity on the lakes [23]. 


\section{Distance from Boats}

More pelicans on LML were found as far away as possible from boats $(>1500 \mathrm{~m})$ than in the other available categories. Large foraging flocks strongly influenced this analysis as they were exclusively detected in the two furthest distance-from-boat categories, suggesting a potential special sensitivity of large groups to boats. Previous studies provide support for this suggestion $[24,25]$. We can conceive of three potential explanations for the finding: (1) pelicans on LML were negatively affected by the presence of boats and moved away from them, (2) pelicans and boats selected different aquatic habitats within distance from shore categories, or (3) the size of the $>1500 \mathrm{~m}$ distance from boat category was much larger than the others, causing a bias for more pelicans to be observed in it. Our data do not allow us to distinguish between these possibilities at this time, and therefore we cannot make firm conclusions regarding disturbance effects on LML. We suggest that future studies incorporate more detailed behavioural observations to document the actual response of pelicans to the arrival of boats.

In contrast to LML, pelican counts on BPL were not affected by distance from boats. This finding was surprising, and interpreting the data in the same manner as that for LML, we can logically propose two explanations for it: (1) pelicans and boaters were selecting common habitats within distance from shore categories; or (2) BPL has limited habitat suitable for boats and pelicans, forcing them to be closer together than expected; i.e., the perceived risk of being near boats was not great enough to override the cost of foregoing feeding. Our data do not allow us to distinguish among these possibilities, although option (2) seems highly unlikely given that even on the busiest boating days there was plenty of near-shore habitat on BPL free of boats that pelicans could have occupied. The reasons for the different responses by pelicans to boats on LML and BPL are potentially important given the different outcomes of our analysis, but remain unclear.

Factors such as breeding and nutritional status and habituation may contribute to differences in pelican behaviours on LML and BPL. For example, we detected many sub-adult birds on BPL, which were identified by brown-grey plumage on the head and wings [4]. Younger birds may not be able to forage as efficiently as adults, and, therefore, may not respond to boat presence because they are unable to expend the energy, or are more motivated to persist in quality foraging locations [9]. Pelicans on BPL also may be habituated to boats because BPL is a relatively small lake where pelicans may have greater exposure to boats. Waterbirds have been observed to flee urban lakes because of disturbance [26], but they have also been observed to be less vigilant and more active foraging near developed shorelines, compared to near undeveloped shorelines [27]. It is possible that pelicans were habituated to boats on BPL because there is less surface area to occupy, and they would be forced to either habituate or leave the lake. Future research should investigate these possibilities more closely, perhaps by focused observations of adult vs. sub-adult response to boating activity.

\section{Management Implications}

Locations used by both breeding and non-breeding birds should be considered in any conservation or management strategy [28]. While it is clear from previous literature that pelican colonies must be strictly protected to prevent reproductive failure and site abandonment [29-31], it is not clear how to manage disturbance of foraging pelicans during the breeding season, or whether recreational boating activities have any negative disturbance-related effects on foraging pelicans at any time. We observed substantial habitat overlap between pelicans and boaters on two important fish-bearing lakes on the northern Great Plains. Shallow water and near shore littoral zones were especially important areas of overlap. However, our point count approach did not reveal any clear or consistent negative effects of habitat overlap between foraging pelicans and recreational boats. Thus, our study shows that habitat overlap between pelicans and boats is not a straightforward management issue. Most waterbirds do not exhibit foraging site fidelity [28], so after flushing, birds likely find another suitable foraging habitat. The birds could also return to the same foraging site after the disturbance has passed [24]. Levels of disturbance by boats on the lakes we studied may not be high enough to be detrimental to pelicans.

Some areas that experience high levels of boating have applied buffer distances to protect other bird species from associated $[3,28,32]$. Our data do not suggest that these buffers are currently necessary for foraging pelicans on LML or BPL. Future research should closely examine the specific behavioural responses of pelicans to the presence of boats, and attempt to estimate the energetic costs associated with flushing and re-distribution, if these occur. From a conservation point of view, recreational boating and foraging pelicans appear to coexist at the current level at the scale that we measured.

\section{CONFLICT OF INTEREST}

The author(s) confirm that this article content has no conflicts of interest.

\section{ACKNOWLEDGEMENTS}

Funding for this study was provided by Saskatchewan Ministry of Environment's Fish and Wildlife Development Fund, the Canadian Wildlife Service, the Natural Sciences and Engineering Research Council of Canada, and the University of Regina. We are most grateful to V. Kjoss for assistance in the field, and R. M. Brigham, A. Crosby, L. Kovatch, S. Hurlbert, and 2 anonymous referees for their useful comments on the manuscript. We would also like to thank J. Keith at the Saskatchewan Conservation Data Center, and R. Poulin at the Royal Saskatchewan Museum for providing the maps.

\section{REFERENCES}

[1] Mikola J, Miettinen M, Lehikoinen E, Lehtila K. The effects of disturbance caused by boating on survival and behaviour of velvet scoter Melanitta fusca ducklings. Biol Conserv 1994; 67: 119-24.

[2] Ronconi RA, Clair CCSt. Management options to reduce boat disturbance on foraging black guillemots (Cepphyrus grille) in the Bay of Fundy. Biol Conserv 2002; 108: 265-71.

[3] Rodgers JA Jr, Schwikert ST. Buffer-zone distances to protect foraging and loafing waterbirds from disturbances by personal watercraft and out-board-powered boats. Conserv Biol 2002; 16: 21624. 
[4] Knopf FL, Evans RM. American white pelican (Pelecanus erythrorhynchos), the birds of North America online. In: Poole A, Ed. Ithaca: Cornell Lab of Ornithology 2004; Retrieved from the Birds of North America Online: http://bna.birds.cornell.edu. libproxy. uregina.ca:2048/bna/species/057doi:10.2173/bna.57

[5] Keith JO. An overview of the American white pelican. Waterbirds 2005; 28 (Special Publication 1): 9-17.

[6] Anderson JGT. Foraging behaviour of the American white pelican (Pelecanus erythrorhyncos) inwestern Nevada. Colonial Waterbirds 1991; 14: 166-72.

[7] Gill JA. Approaches to measuring the effects of human disturbance on birds. Ibis 2007; 149: 9-14

[8] Beale CM, Monaghan P. Behavioural responses to human disturbance: a matter of choice? Anim Behav 2004; 68: 1065-9.

[9] Roney K. Pelicans, cormorants and great blue herons in Saskatchewan in 1976. Blue Jay 1978; 36: 28-35.

[10] Somers CM, Kjoss VA, Leighton FA, Fransden D. American white pelicans and double-crested cormorants in Saskatchewan: population trends over five decades. Blue Jay 2010; 68: 75-86.

[11] Hammer UT. Limnological studies of the lakes and streams of the upper Qu'Appelle River system, Saskatchewan, Canada I. Chemical and physical aspects of the lakes and drainage system. Hydrobiologia 1971; 37: 473-507.

[12] Findholt SL, Anderson SH. Foraging areas and feeding habitat selection of American white pelicans (Pelecanus erythrorhynchos) nesting at Pathfinder Reservoir, Wyoming. Colonial Waterbirds 1995; 18: 47-57.

[13] King DT, Werner SJ. Daily activity budgets and population size of American white pelicans wintering in south Louisiana and the delta region of Mississippi. Waterbirds 2001; 24: 250-4.

[14] Goss NS. Feeding habits of Pelecanus erythrorhynchos. Auk 1988; 5: 25-7.

[15] Lingle GR, Sloan NF. Food habits of white pelicans during 1976 and 1977 at Chase Lake National Wildlife Refuge, North Dakota. Wilson Bull 1980; 92: 123-5.

[16] Doucette JL, Kjoss VA, Somers CM. Size and composition of foraging flights in two species of piscivorous colonial birds: limited evidence for intra- and interspecific information transfer. Open Ornithol J 2008; 1: 48-56.

[17] Diana JS, Mackay WC, Ehrman M. Movements and habitat preference of northern pike (Esox lucius) in Lac Ste. Anne, Alberta. North Am J Fisheries Manage 1977; 106: 560-65.
[18] Ruiz GM, Hines AH, Posey MH. Shallow water as a refuge habitat for fish and crustaceans in non-vegetated estuaries: an example from Chesapeake Bay. Mar Ecol Prog Ser 1993; 99: 1-16.

[19] Schlagenhaft TW, Murphy BR. Habitat use and overlap between adult largemouth bass and walleye in a west Texas reservoir. North Am J Fisheries Manage 1985; 5: 465-70.

[20] Stapanian MA, Bur MT. Overlap in offshore habitat use by doublecrested cormorants and boaters in western Lake Erie. J Great Lakes Res 2002; 28: 172-81.

[21] Klein ML. Waterbird behavioural responses to human disturbances. Wildl Soc Bull 1993; 21: 31-9.

[22] Newbrey JL, Bozek MA, Niemuth ND. Effects of lake characteristics and human disturbance on the presence of piscivorous birds in northern Wisconsin, USA. Waterbirds 2005; 28: 478-86.

[23] Batten LA. Sailing on reservoirs and its effects on water birds. Biol Conserv 1977; 11: 49-58.

[24] Madsen J. Impact of disturbance on field utilization of pink-footed geese in West Jutlans, Denmark. Biol Conserv 1985; 33: 53-63.

[25] Marsden SJ. Impact of disturbance on waterfowl wintering in a U.K. dockland redevelopment area. Environ Manage 2000; 26: 207-13.

[26] Burton NHK, Rehfisch MM, Clark NA. Impacts of disturbance from construction work on the densities and feeding behaviour of waterbirds using the intertidal mudflats of Cardiff Bay, UK. Environ Manage 2002; 30: 865-71.

[27] Traut AH, Hostetler ME. Urban lakes and waterbirds: effects of development on avian behavior. Waterbirds 2003; 26: 290-302.

[28] Rodgers JA Jr, Smith HT. Buffer zone distances to protect foraging and loafing waterbirds from human disturbance in Florida. Wildl Soc Bull 1997; 25:139-45.

[29] Johnson RF, Sloan NF. The effects of human disturbance on the white pelican colony at Chase Lake National Wildlife Refuge, North Dakota. Inland Bird Banding News 1976; 48: 163-70.

[30] Bunnell FL, Dunbar D, Koza L, Ryder G. Effects of disturbance on the productivity and numbers of white pelicans in British Columbia - Observations and Methods. Colonial Waterbirds 1981; 4: 2-11.

[31] Anderson DW, King DT. Introduction: biology and conservation of the American white pelican. Waterbirds 2005; (Special Publication 1): $1-8$.

[32] Rodgers JA Jr, Schwikert ST. Buffer-zone distances to protect foraging and loafing waterbirds from disturbances by airboats in Florida. Waterbirds 2003; 26: 437-43.

Received: December 26, 2013

Revised: February 05, 2014

Accepted: February 12, 2014

(C) Gaudet and Somers; Licensee Bentham Open.

This is an open access article licensed under the terms of the Creative Commons Attribution Non-Commercial License (http://creativecommons.org/licenses/by-nc/3.0/) which permits unrestricted, non-commercial use, distribution and reproduction in any medium, provided the work is properly cited. 